\title{
自然的灵感“偶遇”先进制造技术
}

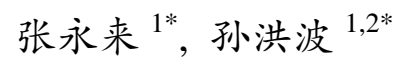

1. 吉林大学电子科学与工程学院, 集成光电子学国家重点实验室, 长春 130012 ;

2. 清华大学精密仪器系, 精密测试技术及仪器国家重点实验室, 北京 100084

* 联系人, E-mail: yonglaizhang@jlu.edu.cn; hbsun@tsinghua.edu.cn

\section{Nature inspired advanced laser fabrication}

\author{
Yong-Lai Zhang $^{1 *} \&$ Hong-Bo Sun ${ }^{1,2 *}$ \\ ${ }^{1}$ State Key Laboratory on Integrated Optoelectronics, College of Electronic Science and Engineering, Jilin University, Changchun 130012, China; \\ ${ }^{2}$ State Key Laboratory of Precision Measurement Technology and Instruments, Department of Precision Instrument, Tsinghua University, Beijing \\ 100084, China \\ * Corresponding authors, E-mail: yonglaizhang@jlu.edu.cn; hbsun@tsinghua.edu.cn
}

doi: 10.1360/N972019-00263

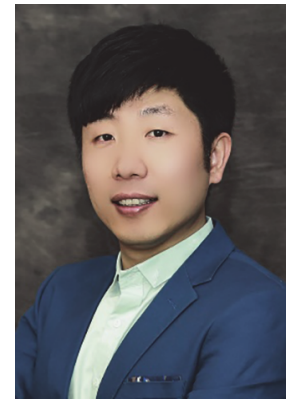

\section{张承来}

教授, 博士生导师, 吉林大学电 子科学与工程学院生物医学工 程系主任; 集成光电子国家重 点实验室. 2011 年入选“香江学 者”计划; 2015 年获得国家优秀 青年科学基金; 2017 年获吉林 省第六批拔尖创新人才称号; 2018 年获吉林省青年科技奖。 主要研究方向为激光仿生制造 与智能器件开发.
大自然是世界上最伟大的“设计师”和“工程师”，经过数亿年的进 化, 自然界的生物通过自身功能结构的不断演变和优化, 展示了独特 的生物特性. 出淤泥而不染的荷叶、阳光下五彩斑斓的彩蝶、擅长攀 岩的壁虎脚、广角侦察的蜻蜓复眼, 这一系列巧夺天工的设计和制造 均出自大自然之手. 人类对这些生物功能的好奇与神往, 驱使研究者 对这些功能独特的生物材料展开了细致的研究, 并逐渐揭开了自然 界生物材料神秘的“面纱”，研究证实微纳尺度的多级结构被认为是产 生上述独特功能的关键. 如今, 人们已经对各类生物材料的微纳结构 与化学组成有了很深的认识, 并试图通过微纳制造技术赋予人造材 料类似、甚至更加优越的特性. 因此, 仿生制造一度成为制造领域的 前沿和研究热点. 然而, 自然界的生物结构形貌十分复杂, 通常是微 米、纳米的多级复合结构, 其三维构型几乎完美, 要想基于人造材料 体系实现可媲美于生物材料的精细结构并非易事, 可以说仿生制造 领域对微纳结构的苛刻要求给现有的微纳加工技术出了一道难题.

作为典型的先进制造技术, 激光微纳加工在三维复杂微纳结构的 制备中显示了强大的技术优势。第一, 激光加工属于非接触式加工, 可以避免物理接触对衬底造成损伤; 第二, 激光加工材料适用范围广, 可以实现多种难加工材料的微纳结构制备; 第三, 激光加工无需掩模 版, 可以实现高精度微纳结构制备, 具有可设计性, 适用于三维结构 制备; 第四, 激光加工在实现微纳成型的同时可以对材料的化学组成 进行有效调控. 上述的一些特点使得激光微纳制造技术成为人造仿 


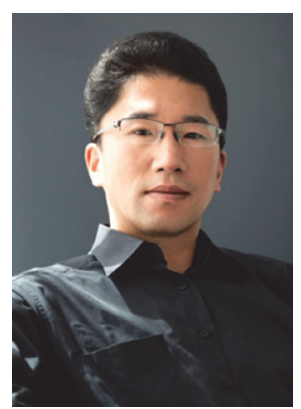

\section{称洪波}

教授, 博士生导师, 清华大学精 密仪器系, “长江学者”特聘教授, 国家杰出青年科学基金获得者, 国家“万人计划”科技创新领军 人才. 2010 年获王大班光学奖 (青年科技奖); 2012 年获吉林省 科学技术一等奖; 2014 年获教 育部自然科学奖一等奖; 2016 年获第七届全国优秀科技工作 者称号. 主要研究方向为超快 激光应用。
生结构制备的理想技术。

近年来，激光微纳加工技术被广泛应用于仿生制造，基于金属、 氧化物、碳材料、聚合物、复合材料等系列功能材料实现了结构化仿 生表面的构建. 尤其是, 通过模仿自然界生物复杂的表面结构和化学 组成, 结合激光加工强大的微纳结构制造能力, 研究者已经成功制备 了仿荷叶超疏水表面、仿鱼鳞水下超疏油表面、仿水稻叶各向异性疏 水表面、仿玫瑰花楸附行超疏水表面等典型结构化仿生表面，同时展 示了这些仿生表面在自清洁、抗结冰、抗雾、减阻、油水分离、液滴 传输等领域的应用前景. 因此, 我们瞄准激光加工在结构化仿生表面 开发中的前沿应用, 邀请国内激光仿生制造领域的知名学者, 共同组 织了“激光制造结构化仿生表面”专题, 收录了 4 篇评述和 3 篇论文. 希望这场大自然的灵感与先进制造技术的“偶遇”可以擦出创新的“火 花”, 照亮激光加工技术的仿生应用之路, 积极推动激光微纳加工在 仿生制造领域快速发展.

谨以本专题献给激光仿生制造研究领域的专家、学者和研究生. 衰心感谢各位专家在百忙之中为本专题撰稿, 是他们的辛勤付出和 大力支持使本专题得以出版. 